\title{
FAST TRACKS: ESTRATÉGIA DE ENFRENTAMENTO DA PANDEMIA DE COVID-19 EM UM HOSPITAL PRIVADO
}

Katyucia Oliveira Crispim de Souza ${ }^{1}$

Gilvan Gomes da Silva ${ }^{1}$

Thalytta Goes Matos Santana ${ }^{1}$

Sheilla Paixão Sampaio Souza ${ }^{1}$

Aline de Carvalho Bastos ${ }^{1}$

Viviane Moreira de Camargo ${ }^{1}$

Alex Vianey Callado Franca ${ }^{1}$

Alysson Santos Oliveira ${ }^{1}$

\begin{abstract}
ORCID: https://orcid.org/0000-0002-1645-4459
ORCID: https://orcid.org/0000-0001-8605-965X

ORCID: https://orcid.org/0000-0002-9131-3955

ORCID: https://orcid.org/0000-0002-4515-7197

ORCID: https://orcid.org/0000-0002-2618-9759

ORCID: https://orcid.org/0000-0003-2771-9755

ORCID: https://orcid.org/ 0000-0003-1362-2135

ORCID: https://orcid.org/0000-0003-4775-0020
\end{abstract}

Objetivo: Descrever as etapas de elaboração e execução de um plano de contingência para a pandemia de coronavirus em um hospital privado com uso de sistema Fast Tracks. Método: Trata-se de um estudo descritivo como relato de experiência com objetivo de elaboração de plano e organização de Fast Track para pacientes com sintomas respiratórios que busquem o setor de urgência do hospital. Resultados: A proposta deste sistema consiste no atendimento de pacientes com Sindrome Gripal de forma isolada ao da Unidade de Urgência, sendo atendidos em ambiente sem contato direto com o setor da urgência. Conclusão: Os Fast Tracks visam otimizar os serviços prestados, e principalmente, a diminuição cruzada do vírus, tão preconizada pelos órgãos mundiais em combate a pandemia, além de evitar a superlotação da unidade de emergência.

Descritores: Pandemias; Triagem; Virus da SARS; Organização e Administração; Assistência Hospitalar.

\section{FAST TRACKS: FACING STRATEGY FOR COVID-19 PANDEMIC IN A PRIVATE HOSPITAL}

Objective: To describe the steps for preparing and executing a contingency plan for the coronavirus pandemic in a private hospital using the Fast Tracks system. Method: This is a descriptive study as an experience report with the objective of developing a plan and organization of Fast Track for patients with respiratory symptoms who seek the emergency department of the hospital. Results: The purpose of this system is to assist patients with Flu Syndrome in isolation from the Emergency Unit, being treated in an environment without direct contact with the emergency department. Conclusion: Fast Tracks aim to optimize the services provided, and mainly, the cross-reduction of the virus, so advocated by world agencies in fighting the pandemic, in addition to avoiding overcrowding of the emergency unit.

Descriptors: Pandemics; Triage; SARS Virus; Organization and Administration; Hospital Care.

\section{FAST TRACKS: ESTRATEGIA DEL ENFRENTAMIENTO DE LA PANDEMIA DEL COVID-19 EN UN HOSPITAL PRIVADO}

Objetivo: Describir los pasos para preparar y ejecutar un plan de contingencia para la pandemia de coronavirus en un hospital privado utilizando el sistema Fast Tracks. Metodo: Este es un estudio descriptivo como un informe de experiencia con el objetivo de desarrollar un plan y organización de Fast Track para pacientes con síntomas respiratorios que buscan el servicio de urgencias del hospital. Resultados: El objetivo de este sistema es ayudar a los pacientes con sindrome de gripe aislados de la unidad de emergencia, que reciben tratamiento en un entorno sin contacto directo con el departamento de emergencias. Conclusión: Fast Tracks tiene como objetivo optimizar los servicios prestados, y especialmente, la reducción cruzada del virus, tan defendido por las agencias mundiales en la lucha contra la pandemia, además de evitar el hacinamiento de la unidad de emergencia.

Descriptores: Pandemias; Triaje; Virus del SRAS; Organización y Administración; Atención Hospitalaria.

${ }^{1}$ Hospital Primavera, Aracaju, SE.

Autor Correspondente: Katyucia Oliveira Crispim de Souza E-mail: katyucia_kk@hotmail.com

Recebido: 22/4/2020 Aceito: 07/6/2020 


\section{INTRODUÇÃO}

$\mathrm{O}$ atual surto do novo coronavírus SARS-CoV-2, teve seu epicentro na província de Hubei, na República Popular da China, de onde se espalhou para muitos outros paises ${ }^{(1)}$. Em 12 de fevereiro de 2020, a Organização Mundial da Saúde (OMS) nomeou oficialmente a doença como Doença de Coronavírus 2019 (Covid-19) e devido sua rápida expansão mundial, no dia 11 de março de 2020 foi declarada como uma pandemia pelo diretor geral Tedros Adhanom Ghebreyesus ${ }^{(2)}$.

No Brasil, em 22 de janeiro de 2020, foi ativado o Centro de Operações de Emergências em Saúde Pública para o novo Coronavirus (COE - nCoV), estratégia prevista no Plano Nacional de Resposta às Emergências em Saúde Pública do Ministério da Saúde ${ }^{(3)}$. Desse modo, em 13 de fevereiro de 2020, o Ministério da Saúde publicou o plano de Contingência Nacional para infecção humana pelo novo coronavirus, que define o nivel de resposta e a estrutura de comando correspondente a ser configurada, em cada nível de resposta.

Dentro do plano destaca-se que, para controlar o Covid-19, as medidas eficazes de prevenção e controle devem incluir detecção, diagnóstico, tratamento e quarentena precoces para bloquear a transmissão de homem para homem, além de reduzir infecções secundárias entre contatos próximos e profissionais de saúde ${ }^{(2)}$. Corroborando com as medidas preventivas, os sistemas de triagem rápido (Fast Tracks) surgem como uma estratégia de barreira e atendimento seguro aos casos suspeitos dessa pandemia.

Assim, o objetivo deste estudo é descrever as etapas de elaboração e execução de um plano de contingência para a pandemia do 2019-nCov em um hospital particular de Aracaju, Sergipe, com uso de Fast Tracks para triagem de pacientes com sintomas respiratórios.

\section{MÉTODO}

\section{Tipo de estudo}

Trata-se de um relato de experiência apresentando as etapas de elaboração e execução de um plano de contingência para a pandemia do 2019-nCov, com uso de Fast Tracks para triagem de pacientes com sintomas respiratórios.

\section{Cenário do estudo}

O estudo foi realizado no Hospital Primavera, uma instituição privada de grande porte localizado na capital sergipana. Inaugurado em 2008, o hospital conta com 182 leitos, sendo que 39 destes fazem parte das Unidades de Terapia Intensiva, possui também 8 salas cirúrgicas e 8 consultórios na ala de urgência. Dispõe ainda de corpo clínico com profissionais de todas as especialidades.

\section{Periodo de realização da experiência}

A experiência foi desenvolvida entre os dias 18 de março a 31 de maio de 2020. Foram coletados no site do hospital (https://www.redeprimavera.com.br/boletin-covid19) os dados referentes ao número de pacientes atendimentos com Síndrome Gripal e seus desfechos. As informações relacionadas ao plano de contingência foram obtidas junto ao Comitê Gestor responsável pela estratégia.

\section{Sujeitos envolvidos na experiência}

Participaram da experiência integrantes do Comitê Gestor, profissionais de saúde responsáveis pela assistência aos pacientes com Sindrome Gripal e integrantes do Comitê de Ética e Pesquisa do hospital.

\section{Aspectos éticos}

O estudo envolveu apenas dados de domínio público disponibilizados no site do hospital sem identificar seus participantes, não se fazendo necessário a submissão ao comitê de ética em pesquisa. Além disso, as imagens apresentadas nos resultados fazem parte do acervo institucional e foram disponibilizadas pelo Comitê Gestor para divulgação.

\section{DESCRIÇÃO DA EXPERIÊNCIA}

Foi criado um comitê composto pela alta liderança do hospital formado pela direção técnica, direção comercial, comissão de controle de infecção hospitalar, gerência de enfermagem, gerência de apoio institucional, gerência de recursos humanos, gerência de suprimentos, medicina do trabalho do hospital, para tomada de medidas mais assertivas e acompanhamento situacional diário da doença no hospital.

Neste comitê, elaborou-se uma série de políticas a fim de enfrentar a pandemia pelo Covid-19, iniciando com a criação de um documento em 16 de março com o objetivo de descrever o planejamento preventivo e alternativo para atuação organizacional durante a pandemia do 2019-nCov. Esse planejamento visou a mobilização de recursos humanos e logísticos com o intuito de garantir o menor dano possível a todos os envolvidos, com o foco em organizar, treinar, orientar, facilitar e uniformizar as ações necessárias ao combate à doença.

A confecção do plano se deu em etapas que obedeceram a seguinte ordem: Identificação e avaliação dos riscos, agrupamento de recursos e organização de estratégias. No documento, além da parte geral que consta os dados, informações, diretrizes e princípios gerais que serão utilizados diante a pandemia, há partes específicas direcionadas para cada setor responsável por realizar os atendimentos.

O plano consta somente de informações estritamente necessárias a fim de facilitar a sua realização e divulgação dentro da organização. A divulgação do plano ocorreu dois dias após a sua elaboração a partir da criação de diversas frentes de trabalho, e uma delas sendo um sistema de triagem mais rápido (Fast Track) para pacientes com sintomas respiratórios que busquem o setor de urgência do hospital. 
A proposta deste sistema consiste no atendimento de pacientes com Síndrome Gripal de forma isolada ao da Unidade de Urgência, sendo atendidos em ambiente sem contato direto com o setor da urgência, evitando assim, a proximidade com os pacientes com queixas não respiratórias. Para isso, foram adquiridos três contêineres e estes ficaram localizados em área específica próxima a área da urgência composto por sala de espera, consultório médico, sala de coleta de exames e pequena observação para aquelas que necessitem de medicação, e ou exame para definição de conduta com independência do setor geral de urgência do hospital (Figura 1).

Figura 1 - Planta baixa da localização dos contêineres no hospital. Aracaju, SE, Brasil, 2020.

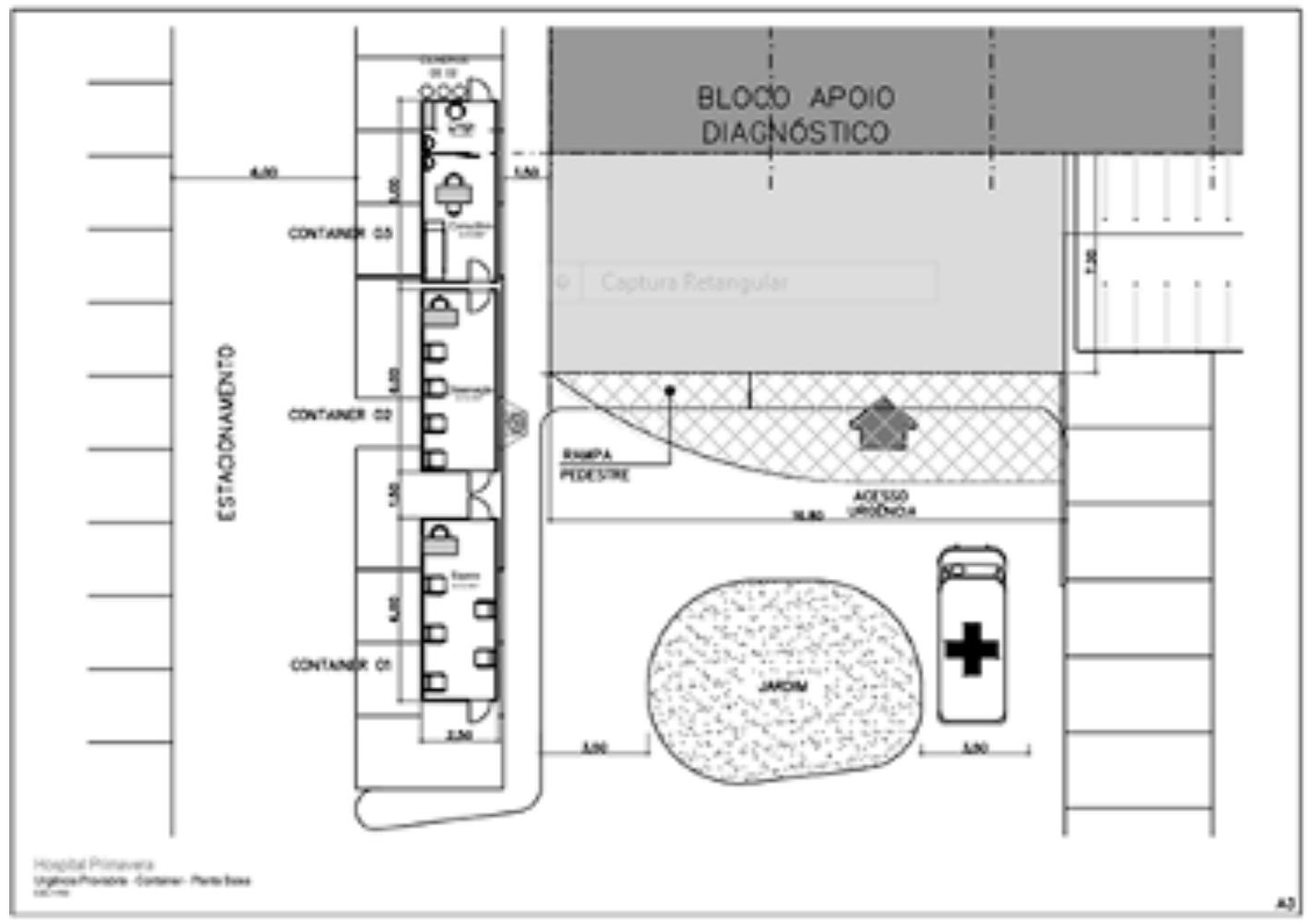

Fonte: Acervo institucional, disponibilizado para publicação.

Durante a avaliação e mediante a classificação de risco, o paciente com sintomas de doença respiratória aguda sem sinais de gravidade será previamente triado por um profissional da equipe de enfermagem, de imediato, ser-lhe-á fornecida máscara cirúrgica comum e solução alcoólica em gel para higiene das mãos. Após esses procedimentos, o paciente será conduzido para sala de espera dentro do Fast Track para o atendimento de pacientes com sintomas respiratórios.

O atendimento médico será realizado em sala exclusiva para esses pacientes de onde poderão ser: 1- Submetidos a coleta de exames específicos para os vírus respiratórios (quando indicado); 2- Ser encaminhados à sala de observação do Fast Track para realização de exames complementares e posterior reavaliação médica; ou 3- Receber alta. Esse fluxo acontece no período das 07:00 às 22:00h e iniciou três dias após sua divulgação. As figuras 2, 3 mostram imagens da parte externa e interna dos contêineres onde são realizados os Fast Track, respectivamente.
Figura 2 - Imagem externa do Fast Track. Aracaju, SE, Brasil, 2020.

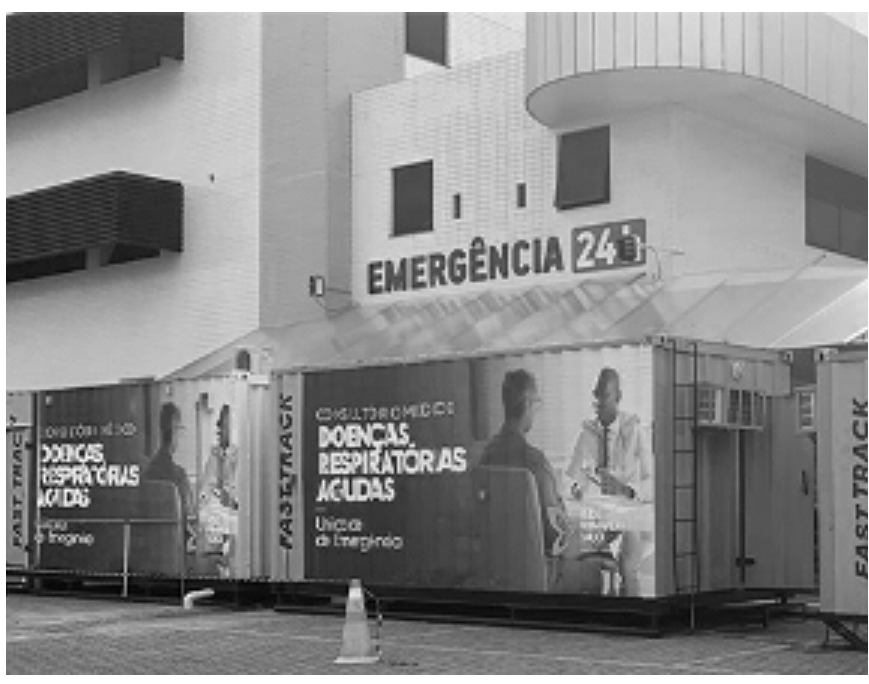

Fonte: Acervo institucional, disponibilizada para publicação. 
Figura 3 - Vista interna do Fast Track destinado ao atendimento de pacientes. Aracaju, SE, Brasil, 2020.

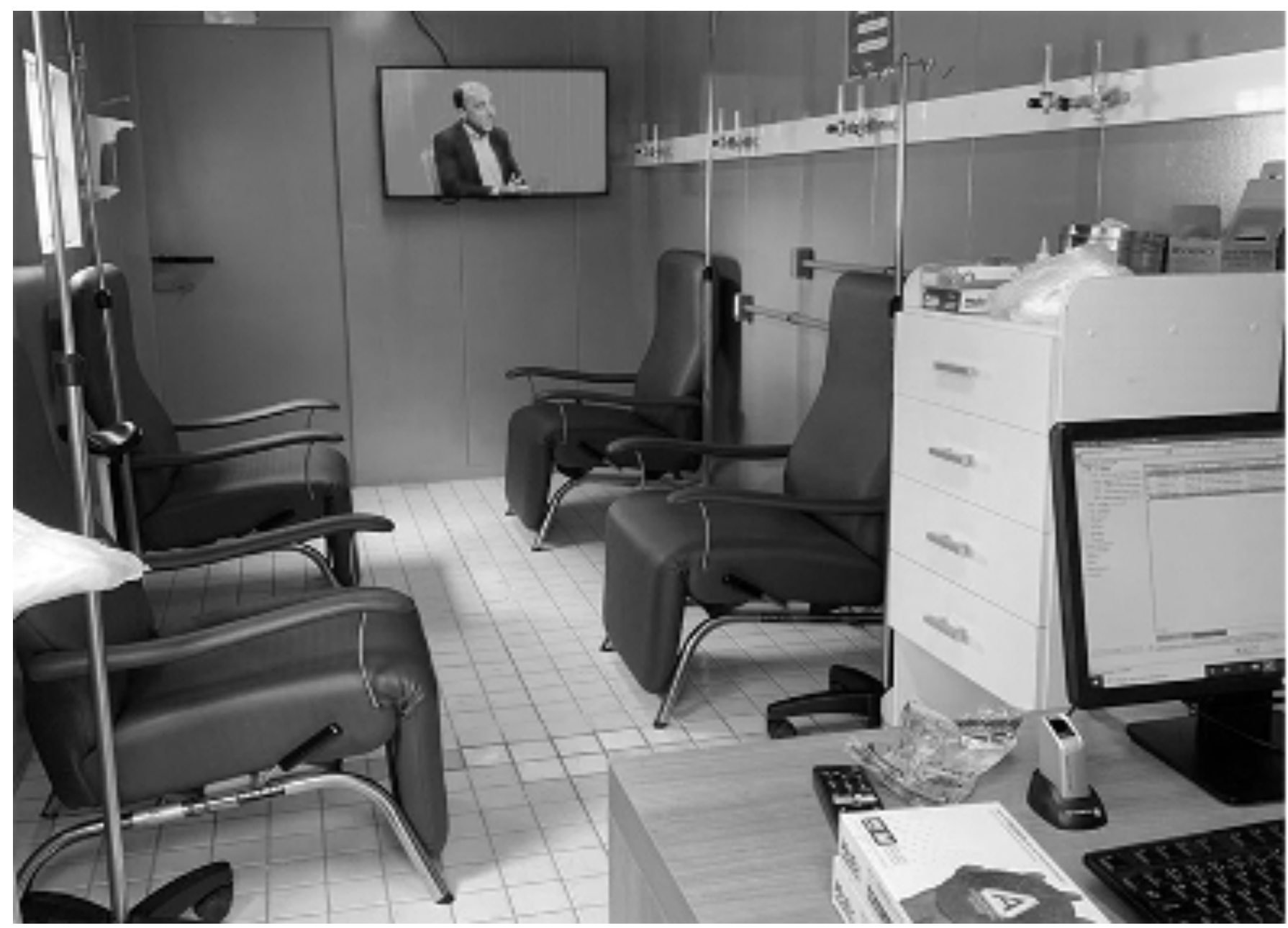

Fonte: Acervo institucional, disponibilizada para publicação.

Os casos mais graves serão encaminhados para o hospital para estabilização e monitoramento em quarto de isolamento específico. Isso envolve indivíduo de qualquer idade, com Síndrome Gripal que apresente dispneia ou os seguintes sinais de gravidade:

- Saturação de oxigênio menor que 95\% em ar ambiente;

- Sinais de desconforto respiratório ou aumento da frequência respiratória avaliada de acordo com a idade;

- Piora nas condições clínicas de doença de base;

- Hipotensão;

- Insuficiência respiratória;

- Em crianças, além dos itens anteriores, observar os batimentos de asa de nariz, cianose, tiragem intercostal, desidratação e inapetência.

Todos os profissionais que atenderem os pacientes com suspeita de Síndrome Gripal não só nos contêineres, mas também dentro do ambiente hospitalar, estarão devidamente paramentados com Equipamentos de Proteção Individual (EPI) que consistem no uso da máscara cirúrgica, luvas, touca, óculos ou protetor facial e aventais descartáveis. Para pro- cedimentos de longa duração e/ou produtores de aerossóis, como coleta do swab orofaríngeo, aspiração de vias áreas e intubação, será utilizado a máscara N95/PFF2 e o face shield, sendo estes últimos EPI os que serão utilizados pela equipe de saúde dos contêineres. Além disso, deve-se realizar a higienização frequente das mãos com água e sabão ou preparação de álcool $70 \%$.

Como forma de garantir a correta disseminação das informações uma outra frente de trabalho foi desenvolvida, denominada como "Times de Treinamento" para treinar coletivamente e/ou individualmente os colaboradores envolvidos no planejamento. A modalidade escolhida foi pelo método On The Job, ou seja, realizado no horário de trabalho, tornando mais fácil a padronização nos métodos de atuação contra o Covid-19. O conteúdo foi abordado considerando a função de cada profissional abrangendo o uso correto de EPI (colocação e retirada) e higienização adequada das mãos, tendo como público alvo toda equipe que estará envolvida no atendimento a estes pacientes: que vão deste a equipe de enfermagem, médicos, biomédicos, fisioterapeutas, psicólogos, 
higienização, hotelaria até os demais setores administrativos que permeiam a assistência direta ou indireta aos pacientes.

\section{PRINCIPAIS RESULTADOS ALCANÇADOS}

A equipe multidisciplinar, composta pela equipe de enfermagem, médicos, biomédicos, fisioterapeutas, psicólogos, higienização, hotelaria e demais setores administrativos que atuam na linha de frente da assistência de casos suspeitos e confirmados, receberam treinamentos a respeito das ações do plano de contingência, assim como toda a equipe que compõe o hospital, através de um time de treinamentos que fora montado e é responsável por atualizar esses profissionais buscando a uniformidade da informações, auxiliando na melhor assistência, além de promover a manutenção da segurança individual e coletiva; favorecendo a melhoria do desempenho dos profissionais e consequentemente da empresa.

Desde o início do plano de contingência, foram atendidos 3728 pacientes com Síndrome Gripal, sendo que 1919 (51,5\%) destes foram submetidos a exames para detecção do Covid-19, resultado em 547 (28,5\%) positivos. No último dia do mês de maio, havia 8 casos suspeitos e 11 confirmados no setor do internamento. Na Unidade de Terapia Intensiva do hospital, havia 7 caoses suspeitos e 9 confirmados. O gráfico 1 ilustra o número de pacientes suspeitos e confirmados desde o início dos atendimentos no Fast Tracks.

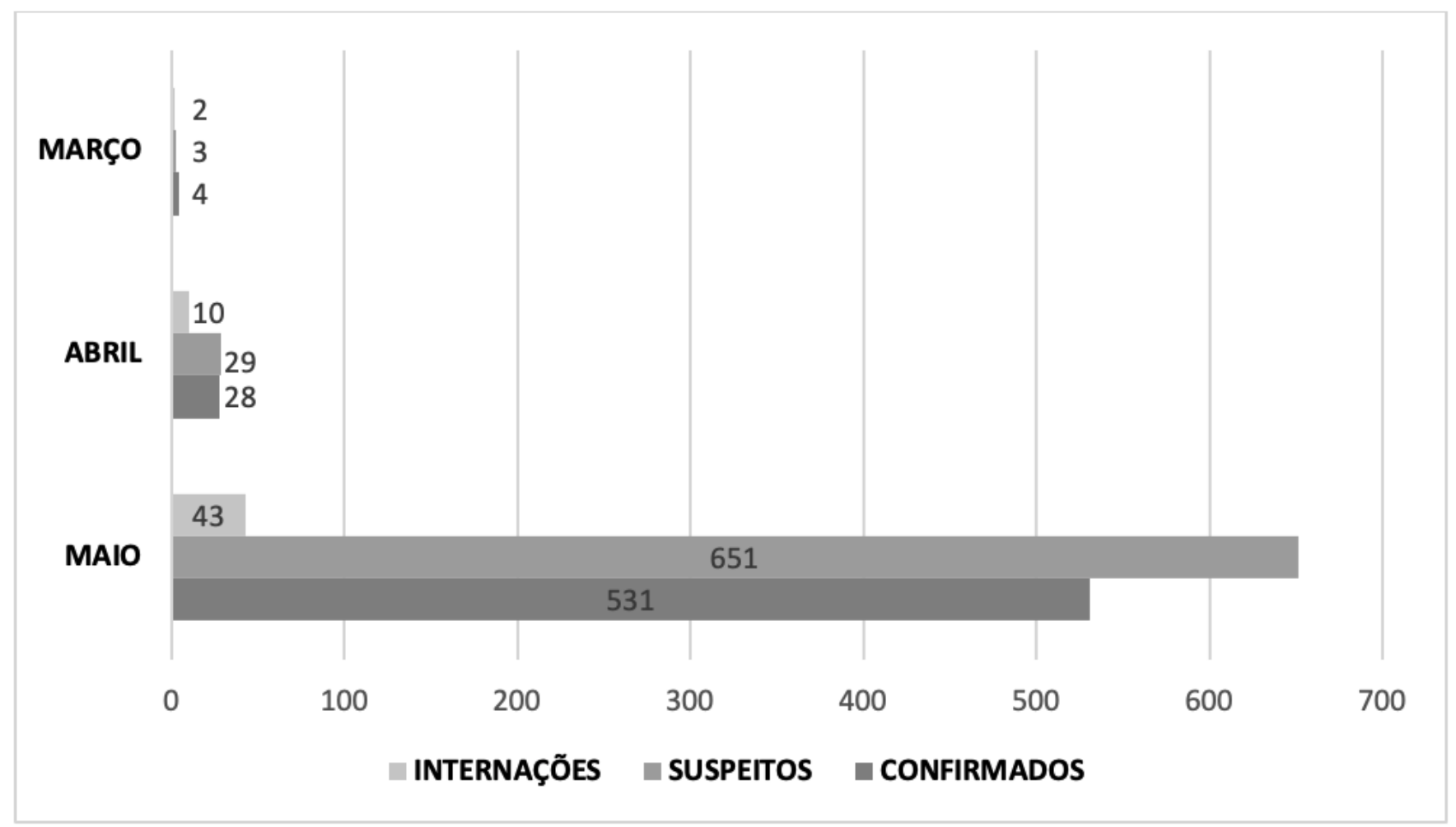

Fonte: Dados do Boletim Diário COVID-19 divulgados pelo site da instituição.

A partir dos resultados alcançados com esta experiência até o momento, destaca-se que a detecção e o isolamento precoces dos casos é de suma importância além da ampliação da testagem dos casos suspeitos com entrega rápida dos resultados. A OMS recomenda evitar o contato próximo com pessoas que sofrem de infecções respiratórias agudas e que dentro dos estabelecimentos de saúde devem ser aprimoradas as práticas padrão de prevenção e controle de infecções ${ }^{4}$.
De acordo com a recomendação do Ministério da saúde, a utilização de Fast Tracks, visam a otimização dos serviços prestados, e principalmente a diminuição da transmissão de novos casos, evitando a superlotação em unidade de emergência. A organização do fluxograma, possibilita a triagem dos pacientes, classificando quanto a gravidade, e eles são direcionados às unidades de acordo com o grau de risco. Alguns pacientes irão necessitar de suporte mais intensivo, onde são encaminhados para a unidade interna do hospital, 
que dispõe de leitos que possibilitam o seu isolamento ${ }^{5}$.

$\mathrm{Na}$ linha de frente destas ações estão aqueles da área de enfermagem que têm atuado de forma conjunta para prevenir, combater a propagação e tratar os infectados pelo novo Corona vírus. A enfermagem sempre exerceu papel fundamental nas ações de proteção aos individuos, considerando os determinantes sociais que estão envolvidos na questão da transmissão e do aumento do número de $\operatorname{casos}^{6}$, sendo uma categoria indispensável num cenário de pandemia.

No contexto da pandemia, os enfermeiros estão contribuindo na identificação das pessoas com sintomas, nas orientações de combate à doença, nos contatos diretos às pessoas infectadas e nas ações de prevenção. Para que possam desempenhar seu papel com eficácia, além das questões técnicas e práticas, esses profissionais devem ser atualizados diariamente sobre a doença. É necessário que as informações sejam incorporadas de uma forma rápida e prática e relacionando a teoria com a prática para que a enfermagem possa prestar um cuidado à população de uma forma mais segura?

Outra medida de extrema importância é a utilização de equipamentos de proteção individual que devem ser utilizadas por todos os profissionais de saúde para prevenir e evitar a disseminação de novos casos do (SARS-Cov-2). Os materiais foram definidos pelo Ministério da Saúde como forma de proteção e seu uso é indispensável, mas é importante salientar que devem ser destinados apenas a profissionais de saúde ou casos suspeitos, o uso inadequado pela população acaba gerando déficit dos materiais nas instituições de saúde ${ }^{3}$.

As experiências internacionais apontam para a necessidade de controle da velocidade de progressão de novos casos por meio de medidas de isolamento físico social frente à impossibilidade de controle imediato da pandemia por meio de vacinação ${ }^{8}$. É importante refletir que a literatura já apresenta certa robustez teórico-prática sobre o status de adoecimento e a prevenção de novos casos da doença. Isso se justifica pela possibilidade de identificação precoce dos casos positivos, a adoção de ações de isolamento e, consequentemente, a redução nos indicadores de reprodução da doença9.10.

A forma como as instituições provedoras de cuidados organiza suas atividades de trabalho e a análise de como se processam tem um papel relevante e deve ser considerado na estratégia de enfrentamento da Covid-19. Pouco se discute sobre as condições e organização do trabalho, prevalecendo, até o momento, protocolos com recomendação de medidas individuais (higiene e uso de equipamentos de proteção), fundamentais, mas insuficientes para o controle geral da disseminação e da exposição ao vírus ${ }^{11}$

\section{Limitações da experiência}

Dentre as desvantagens, o estudo apresenta limitações como a impossibilidade de generalizar os resultados obtidos com conclusões específicas para os casos estudados, não permitindo conclusões genéricas. Para isso, seria necessário uma metodologia mais apurada e mais tempo para coleta e análise dos dados

\section{Contribuições para a prática}

Os resultados desta experiência concentram-se principalmente nas repercussões para a prática clínica dos profissionais de saúde que atuam na linha de frente no cuidado aos pacientes com Síndrome Gripal. As contribuições do sistema Fast Track como ferramenta de fluxo rápido de triagem para todo paciente confirmado ou suspeito de Covid-19 visam organizar as atividades de trabalho evitando a superlotação em unidade de emergência e principalmente, a diminuição cruzada do vírus. Outro aspecto de grande valia foi a experiência de organização do fluxograma através de uma triagem rápida, classificando os pacientes quanto a gravidade, direcionando-os às unidades de acordo com o grau de risco e necessidade de suporte mais intensivo.

\section{CONSIDERAÇÕES FINAIS}

Diante de uma situação de crise gerada por uma doença de dimensão mundial, a capacidade de organização com diversas frentes de trabalho e de forma sinérgica de uma instituição, favorece além de uma contribuição a população como prestadora de serviços, ações que a transpõe, visando a saúde pública da região. A utilização do sistema Fast Tracks como uma estratégia de barreira e atendimento seguro para triagem de pacientes com sintomas respiratórios visou otimizar os serviços prestados, evitar a superlotação da unidade de emergência e, principalmente, a diminuição da contaminação cruzada do vírus, tão preconizada pelos órgãos mundiais no combate à pandemia.

Somado a isso, a disseminação das ações educativas são importantes estratégias e devem estar presentes no processo de trabalho, garantindo melhoria no desempenho dos profissionais, e consequentemente, da empresa.

Contribuição dos Autores: Concepção, planejamento, análise, interpretação e redação do trabalho: Katyucia Oliveira, Gilvan Gomes e Thalytta Goes; análise do manuscrito, considerações e correções: Aline de Carvalho, Sheilla Paixão, Viviane Moreira de Carvalho, Alex Vianey Callado França. Todos os autores aprovaram a versão final encaminhada. 


\section{REFERÊNCIAS}

1. Velan, TP, Meyer, CG. The COVID-19 epidemic. Trop Med Int Health. 2020;25(3):278-280. https://doi.org/10.11ll/ tmi.13383

2. Organização Mundial da Saúde (OMS). [Internet]. Discurso de abertura do Diretor-Geral da OMS na conferência de impressa sobre COVID-19, realizado em 11 de março de 2020 [cited 2020 Mar 25]. Available from: https://www.who.int/es/dg/speeches/detail/who-director-general-s-opening-remarks-at-the-mediabriefing-on-Covid-19---11-march-2020

3. Agência Nacional de Vigilância Sanitária (ANVISA).. Orientações para serviços de saúde: medidas de prevenção e controle que devem ser adotadas durante a assistência aos casos suspeitos ou confirmados de infecção pelo novo coronavirus (SARS-cov-2), Brasilia, 2020a.

4. Lai C-C, Shih T-P, Ko W-C, Tang H-J, H P-R. Severe acute respiratory syndrome coronavirus 2 (SARSCoV-2) and coronavirus disease-2019 (COVID-19): The epidemic and the challenges. International Journal of Antimicrobial Agents. 2020:55(105924):1-9. doi: https://doi.org/10.1016/j.jantimicag.2020.105924.

5. Ministério da Saúde (BR). Fast-Track para a atenção primária em locais com transmissão comunitária-fluxo rápido, Brasilia, 2020b.

6. Grabois V, Rosa MB. Aprendendo com a sabedoria da linha de frente do cuidado. Rev Gaúcha Enferm. 2019;40(esp):e20180487. doi: https://doi.org/10.1590/1983-1447.2019.20180487.

7. Tibola TSA, Cordeiro ALPC, Stacciarini TSG, Engel RH, Costa DG, Haas VJ. Fatores que Influenciam a Participação dos Profissionais de Enfermagem na Educação Permanente em Hospital Público. Enferm Foco. 2019;10(2):11-16. doi: https://doi.org/10.21675/2357-707X.2019.v10.n2

8. Rafael RMR, Neto M, Carvalho MMB, David HMSL, Acioli S, Faria MGA. Epidemiologia, políticas públicas e Covid-19. Rev enferm UERJ. 2020;28:e49570. doi: http://dx.doi.org/10.12957/reuerj.2020.49570

9. World Health Organization (WHO). Report of the WHO China Joint Mission on Coronavirus Disease 2019 (COVID-19) [Internet]. Geneve: WHO; 2020 [cited 2020 Apr 20]. Available from: https://www.who.int/docs/ default-source/coronaviruse/who-chinajoint-mission-on-covid-19-final-report.pdf

10. Li R, Pei S, Chen B, Song Y, Zhang T, Yang W, et al. Substantial undocumented infection facilitates the rapid dissemination of novel coronavirus (SARS-CoV2). Sience [Internet]. 2020 [cited 2020 Mar 25], preprint. doi:https://doi.org/10.1126/science.abb3221

11. Jackson Filho JM, Assunção AA, Algranti E, Garcia EG, Saito CA, Maeno M. et al. A saúde do trabalhador e o enfrentamento da COVID-19. Rev Bras Saude Ocup 2020:45:el4. doi:https://doi.org/10.1590/23176369ED0000120 